\title{
A PCR Assay for Specific Detection of the Pandemic Vibrio parahaemolyticus 03:K6 Clone from Shellfish
}

\author{
P.S. MARIE YeUnG, A. DePaOla, C.A. KaYSNER, AND K.J. BooR
}

\begin{abstract}
The current standard method for identifying Vibrio parahaemolyticus serotype 03:K6, an emerging pathogen with apparent enhanced virulence characteristics, typically takes 4 to $6 \mathrm{~d}$ to complete and requires serotyping. To provide a more rapid strategy, we optimized a polymerase chain reaction (PCR)-based assay for specific detection of $\mathrm{V}$. parahaemolyticus $03: \mathrm{K}$. Of $78 \mathrm{~V}$. parahaemolyticus isolates and other related species; only strains classified into the $V$. parahaemolyticus 03:K6 clonal group $(n=39)$ showed positive results in the PCR assay. The assay detected 2.3 cells/PCR reaction and 310 cells/g using bacterial cultures and inoculated oyster samples, respectively. Sensitive and specific detection of $V$. parahaemolyticus 03:K6 was possible following a 6-h enrichment.

Keywords: rapid detection, Vibrio parahaemolyticus 03:K6, polymerase chain reaction (PCR), shellfish
\end{abstract}

\section{Introduction}

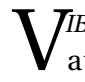
IBRIO PARAHAEMOLYTICUS IS A GRAM-NEGative microorganism that is naturally present in estuarine environments (Baross and Liston 1968). Although V. parahaemolyticus infections occur quite frequently in some countries such as Japan and Taiwan (Pan and others 1997; Murase and others 2001), the majority of $V$. parahaemolyticus strains is not thought to be pathogenic (Miyamoto and others 1969). This hypothesis is based on epidemiological data that showed that among isolates examined, only about $1 \%$ of environmental isolates but nearly all human clinical isolates (about 95\%) expressed the thermostable direct hemolysin (Tdh), a hemolysin responsible for beta-hemolysis on Wagatsuma blood agar (referred to as the Kanagawa phenomenon, KP). The presence of the $t d h$ gene, which encodes Tdh, has been used as a marker for identifying pathogenic $V$. parahaemolyticus strains (Nishibuchi and others 1985; Shirai and other 1990).

V. parahaemolyticus infections have been traced back most frequently to oyster consumption (Hlady and Klontz 1996). Given the ubiquitous presence of this organism in the marine environment, preventing contamination of shellfish with V.parahaemolyticus is virtually impossible. Therefore, to prevent V. parahaemolyticus infections or to determine the safety of reopening shellfish growing areas following an outbreak, regulatory agencies and the seafood industry need rapid methods to detect pathogenic $V$. parahaemolyticus that may be present in a variety of matrices.
V. parahaemolyticus detection methods based on assessing the presence of the genes encoding Tdh or Tdh-related hemolysin (Trh) have been described by several groups (Lee and others 1992; Lee and Pan 1993; Karunasagar and others 1996; Bej and others 1999). For example, Lee and others (1992) described an oligonucleotide probe targeting $t d h$ for use in a colony hybridization assay. Bej and others (1999) described a multiplex PCR-based assay for detecting hemolysin-producing V. parahaemolyticus strains in shellfish. Some of these assays may detect nonpathogenic strains that bear, but do not express, $t d h$ or $t r h$. Nevertheless, these assays show promise for rapid screening for the presence of potentially pathogenic V. parahaemolyticus (that is, $t d h$ or $t r h$-positive strains). On the other hand, these assays also may not detect all pathogenic $V$. parahaemolyticus since it has been reported that some $t d h$-negative and/or $t r h$ negative strains can cause human disease (Kelly and Stroh 1989). The inclusion of additional appropriate virulence gene markers in assays such as those based on multiplexPCR strategies might enhance detection capabilities for pathogenic V. parahaemolyticus.

FoodNet data from the Centers for Disease Control and Prevention (CDC) showed that the incidence of Vibrio infections in the United States increased sharply in 1997 and 1998 relative to 1996 (CDC 1999, 2002). The increased incidence was largely attributed to a multistate $V$. parahaemolyticus outbreak in 1997 (CDC 1998) and the emergence of V.parahaemolyticus O3:K6 in 1998
(Daniels and others 2000). Since 1996, V. parahaemolyticus O3:K6 caused multiple large-scale human disease outbreaks, not only in the United States, but also in Taiwan, India, and Japan. Although several research groups have characterized V. parahaemolyticus O3:K6 strains in an attempt to elucidate the mechanisms underlying its apparently enhanced virulence and/or transmissibility (Okuda and others 1997; Daniels and others 2000; Wong and others 2000; Bhuiyan and others 2002; Osawa and others 2002a; Yeung and others 2002), specific and sensitive detection of this pathogen still presents a challenge. Nonetheless, Nasu and others (2000) and Matsumoto and others (2000) identified a phage-encoded open reading frame (ORF8) and a conserved toxRS allele, respectively, which both appear to be good markers for V. parahaemolyticus O3:K6. In addition, Khan and others (2002) also reported an ERIC DNA sequence unique to O3:K6. Although there is no evidence that these sequences, which are unique to $\mathrm{O} 3: \mathrm{K} 6$, have a direct functional link with enhanced virulence, they appear to provide suitable targets for DNA-based specific detection methods for V. parahaemolyticus O3:K6.

The current standard method for identifying V. parahaemolyticus O3:K6 strains requires serotyping. This method is expensive, tedious, and time-consuming, requiring isolation of a pure culture. We reasoned that a molecular approach could allow more rapid detection of V. parahaemolyticus O3:K6. Thus, the objective of this study was to develop and evaluate a PCR-based method 
for the specific detection of V. parahaemolyticus O3:K6 from bacterial colonies and oyster samples. We specifically selected ORF8 as a target gene for our PCR assay, since multiple lines of evidence suggested the hypothesis that this gene is unique to V. parahaemolyticus O3:K6 (Nasu and other 2000; Osawa and others 2002b; Yeung and others 2002).

\section{Materials and Methods}

\section{Bacterial isolates and media}

All isolates used in this study are shown in Table 1. Serotypes were determined by the CDC. All isolates were grown in tryptic soy agar (TSA; Difco Laboratories, Detroit, Mich., U.S.A.) supplemented with $2 \% \mathrm{NaCl}$ (TSAS) and streaked for isolation of single colonies. Isolates were stored in tryptic soy broth supplemented with $2 \% \mathrm{NaCl}$ (TSBS) and $20 \%$ glycerol at $-80{ }^{\circ} \mathrm{C}$.

Serotype O4:K68 and O1:KUT strains (FSL-Y1-014 and FSL-Y1-015, respectively) had been reported previously as genetically similar to recent O3:K6 isolates as they share similar arbitrarily primed PCR fingerprints, ribotype and pulsed-field gel electrophoresis patterns (Chowdhury and others 2000; Matsumoto and others 2000). Therefore, these 2 strains were classified into the $\mathrm{O} 3: \mathrm{K} 6$ clonal group. On the other hand, "old O3:K6" isolates (FSL-Y1-021 and FSL-Y1-022) were classified into the nonO3:K6 group since they exhibited different genotypes than O3:K6 strains isolated after 1996 (Chowdhury and others 2000; Matsumoto and others 2000).

\section{Preparation of lysates from bacterial cultures}

To prepare bacterial cell lysates, isolates were inoculated into TSBS and incubated at $37^{\circ} \mathrm{C}$ overnight with shaking at $250 \mathrm{rpm}$. Aliquots of $250 \mu \mathrm{L}$ from overnight cultures were centrifuged for $5 \mathrm{~min}$ at $13000 \times \mathrm{g}$. Pellets were resuspended in $95 \mu \mathrm{L}$ of $1 \mathrm{X}$ PCR buffer (Gibco BRL ${ }^{\circledR}$, Life Technologies, Rockville, Md., U.S.A.) and then treated with $4 \mu \mathrm{L}$ of $50 \mathrm{mg} / \mathrm{mL}$ lysozyme (that is, $2 \mathrm{mg} / \mathrm{mL}$ final concentration). After incubation at $37^{\circ} \mathrm{C}$ for $15 \mathrm{~min}, 1 \mu \mathrm{L}$ of $20 \mathrm{mg} / \mathrm{mL}$ Proteinase $\mathrm{K}$ was added to the mixture (that is, $200 \mu \mathrm{g} / \mathrm{mL}$ final concentration). The mixture underwent a further incubation at $60{ }^{\circ} \mathrm{C}$ for $1 \mathrm{~h}$ before heating in a boiling water bath for 8 min to denature Proteinase K. Bacterial lysates were stored at $-20^{\circ} \mathrm{C}$ until use, and 1 $\mu \mathrm{L}$ aliquots were used as PCR templates.

\section{ORF8-PCR}

Primers ORF8-F (5' GTT CGC ATA CAG TTG AGG 3') and ORF8-R (5' AAG TAC AGC AGG AGT GAG 3') (Nasu and others 2000) were used to amplify a 746-bp fragment of the ORF8 region of phage $\mathrm{f} 237$. PCR was performed in a $25-\mu \mathrm{L}$ reaction volume in a GeneAmp PCR System 2400 (Perkin-Elmer, Foster City, Calif., U.S.A.). Each reaction mixture had a final concentration of 1X PCR buffer (Gibco), $1.5 \mathrm{mM} \mathrm{MgCl}_{2}, 100 \mu \mathrm{M}$ of each dNTP, $1 \mu M$ of each primer, $1 \mathrm{U} / 25 \mu \mathrm{L}$ Taq Polymerase (PE Applied Biosystems, Foster City, Calif., U.S.A.). After preincubation at $94^{\circ} \mathrm{C}$ for $5 \mathrm{~min}$, amplification was performed for 35 cycles of $94^{\circ} \mathrm{C}$ for $30 \mathrm{~s}$, $58^{\circ} \mathrm{C}$ for $30 \mathrm{~s}$, and $72{ }^{\circ} \mathrm{C}$ for $60 \mathrm{~s}$, which were followed by holding at $72{ }^{\circ} \mathrm{C}$ for $7 \mathrm{~min}$. Aliquots of 5- $\mu \mathrm{L}$ PCR product were separated in $1.5 \%$ agarose gels and subsequently visualized by UV illumination after ethidium bromide staining.

\section{tlh-PCR}

Primers $t l h$-F (5' AAA GCG GAT TAT GCA GAA GCA CTG 3') and $t h$-R (5' GCT ACT TTC TAG CAT TTT CTC TGC 3') were used to amplify a 450 -bp fragment of the thermolabile hemolysin gene (Bej and others 1999). The PCR conditions were identical to those for the ORF8-PCR.

\section{Southern blot hybridization}

Southern blot hybridization was performed to confirm the presence of ORF8 in selected isolates. After overnight incubation with shaking ( $250 \mathrm{rpm})$ at $37^{\circ} \mathrm{C}$ in TSBS, bacterial cells from 1-mL samples were collected by centrifugation at $13000 \mathrm{rpm}$ for 5 min. Genomic DNA was prepared by using the QIAamp ${ }^{\circledR}$ DNA Mini Kit (Qiagen Inc., Valencia, Calif., U.S.A.). DNA purity and concentrations were determined using a Beckman DU ${ }^{\circledR} 640$ spectrophotometer (Beckman Coulter, Fullerton, Calif., U.S.A.). Southern blot hybridization was carried out according to standard procedures (Ausubel and others 1995). The probes for ORF8 were synthesized using PCR as described above, but modified to incorporate digoxigenin-11dUTP (Roche Diagnostics Corp. Indianapolis, Ind., U.S.A.) as a label into PCR products. Genomic DNA $(2.5 \mu \mathrm{g})$ was digested with EcoRI or HindIII, and the resulting DNA fragments were separated in an agarose gel and transferred to a nylon membrane. Probes were hybridized at $55^{\circ} \mathrm{C}$ in the presence of a Blocking Reagent (Roche Diagnostics). An anti-digoxigenin-AP Fab fragment (Roche Diagnostics) and CDP-Star (Roche Diagnostics) were used to detect the presence of target sequences.

\section{Determination of PCR sensitivity}

To determine the sensitivity of ORF8PCR using bacterial cultures, bacterial lysates were diluted serially and $1 \mu \mathrm{L}$ of each dilution was used as DNA template. The initial density of bacterial cultures (prior to lysate preparation) was determined by standard plate counts on TSAS.

To determine the sensitivity of the ORF8PCR assay on oyster samples, overnight cultures of $V$. parahaemolyticus were serially diluted and $100 \mu \mathrm{L}$ of each dilution was inoculated into $1 \mathrm{~mL}$ of diluted oyster homogenates (corresponding to $0.1 \mathrm{~g}$ of oyster) prepared from canned oysters as described below. PCR was conducted on these samples following enrichment and preparation of oyster lysates, as described below.

\section{Preparation of inoculated oyster samples}

The $t$ lh- and ORF8-PCR assays were further optimized using oyster samples. Twenty-five grams of canned oysters purchased from a local grocery store were blended with $25 \mathrm{~mL}$ of phosphate buffered saline (PBS) for $2 \mathrm{~min}$ at high speed. Twenty $\mathrm{g}$ of the 1:1 diluted oyster homogenates were then homogenized with $80 \mathrm{~mL}$ of PBS to yield a final 1:10 dilution of the oyster homogenates. To reduce and eliminate the indigenous microbial population, the 1:10 diluted oyster homogenates were exposed to UV light for at least $1 \mathrm{~h}$ with shaking, and then to 3 cycles of freezing at $-80^{\circ} \mathrm{C}$ followed by thawing at room temperature (Brasher and others 1998). Inoculation of different concentrations of V.parahaemolyticus cells into $1 \mathrm{~mL}$ of 1:10 diluted oyster homogenates was immediately followed by addition of $30 \mathrm{~mL}$ of alkaline peptone water (APW). The mixtures were incubated at $37^{\circ} \mathrm{C}$ for $6 \mathrm{~h}$ and $18 \mathrm{~h}$. Following each enrichment period, $500-\mu \mathrm{L}$ aliquots were held at $-20^{\circ} \mathrm{C}$ in $1.5-\mathrm{mL}$ microcentrifuge tubes. Inoculated oyster homogenates without enrichment broth (" $0 \mathrm{~h}$ enrichment") and uninoculated oyster homogenates (negative controls) were also prepared.

\section{Preparation of lysates from inoculated oyster samples}

Four lysate preparation methods were used to prepare bacterial DNA for PCR from the oyster homogenates (Lee and others 1995; Brasher and others 1998). The 4 methods were designated as method A, B, C, and $D$, respectively. Table 2 shows the procedures for methods A, B, and C. Method D was not amenable to summary in table format and is described below. In method D, $500 \mu \mathrm{L}$ of the oyster homogenate mixture was mixed with Chelex ${ }^{\mathrm{TM}} 100$ (Bio-Rad Laboratories, Hercules, Calif., U.S.A.) to yield a final concentration of $18 \%$ Chelex $^{\mathrm{TM}}$. The mixture was heated to $58^{\circ} \mathrm{C}$ for $10 \mathrm{~min}$ and then boiled for $20 \mathrm{~min}$. Ammonium acetate 


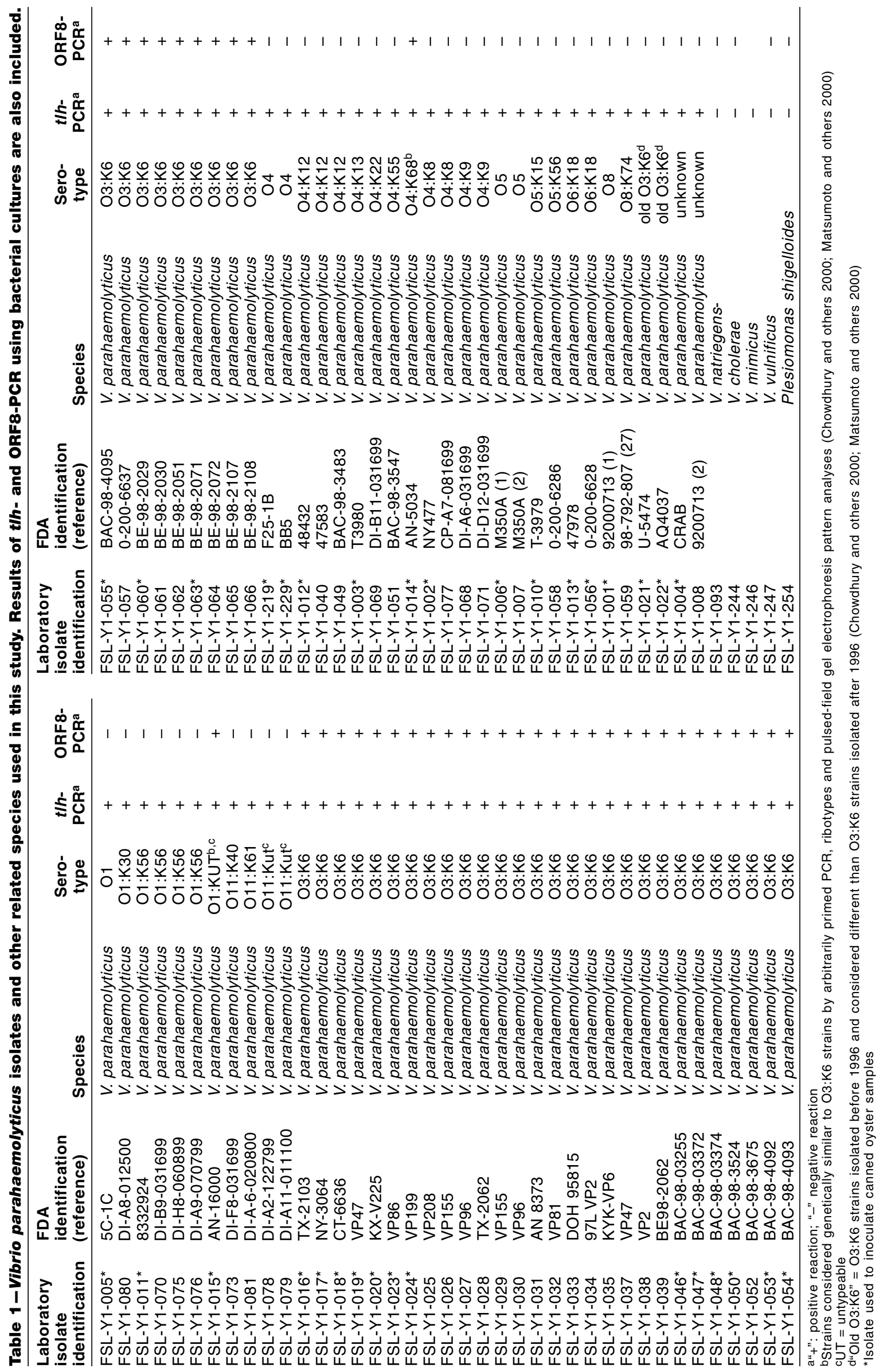


(3 $M$ final concentration) and an equal volume of chloroform: isoamyl alcohol (24:1 vol/ vol) were then added to purify the DNA. After centrifugation, the aqueous phase (containing the DNA) was removed and mixed with 0.6 volume of ice-cold isopropanol to precipitate the DNA, which was subsequently washed once with $70 \%$ icecold ethanol. The DNA was dried under vacuum and resuspended in $50 \mu \mathrm{L}$ TE buffer. When oyster samples were tested for $t h$ and ORF8-PCR, 5- $\mu \mathrm{L}$ aliquots of undiluted and diluted (1:5 and/or 1:10 dilution) oyster lysates were used as the templates for PCR amplification. As Method D was both less reliable and more complicated than Methods A, B, or C, the results from this lysate preparation method are not reported herein.

\section{Collection and shipment of fresh oysters}

To evaluate the application of our assays on fresh oyster samples, 4 batches of oysters were collected from Long Island Sound, N.Y., U.S.A., in September 2001. For each batch, 13 to 15 oysters were collected in heavy-duty plastic bags and placed in insulated shipping containers with frozen ice packs, insulation materials, and a thermometer. The containers were shipped to the laboratory immediately. Upon arrival, the temperatures inside the containers were recorded. The internal temperature of 1 oyster from each batch was measured by inserting a thermometer into the oyster meat for $30 \mathrm{~s}$. For all batches, internal temperatures were below $10^{\circ} \mathrm{C}$. Oyster samples were analyzed within $36 \mathrm{~h}$ after harvesting.

\section{Testing of fresh and uninoculated oyster samples using modified} standard microbiological methods

Standard microbiological methods were performed according to the Food and Drug Administration's (FDA) Bacteriological Analytical Manual (BAM) (FDA 2001) with some modifications. From each batch, 12 to 14 oysters were scrubbed under running deionized water and then shucked with a sterile shucking knife. Approximately 200 to $250 \mathrm{~g}$ of the interior contents of the oysters was collected in a sterile stomacher bag. PBS was added to constitute a 1:1 dilution (wt/ wt). The mixture was blended in a commercial blender at high speed for 2 min. Fifty $g$ of the 1:1 diluted homogenates were then homogenized with $200 \mathrm{~mL}$ of PBS in a stomacher at high speed for $30 \mathrm{~s}$ to constitute a final 1:10 dilution of the oyster homogenates. To quantify $V$. parahaemolyticus numbers in oyster samples, a 3-tube most probable number (MPN) was used. Serial

Table 2-Methods to prepare bacterial DNA from oyster homogenates for PCR assays

\begin{tabular}{|c|c|c|c|}
\hline & \multicolumn{3}{|c|}{ Oyster Iysate preparation method } \\
\hline & Method A & Method B & Method C \\
\hline Procedure & $\begin{array}{c}500-\mu L \text { oyster } \\
\text { homogenate mixture } \\
\downarrow \\
100{ }^{\circ} \mathrm{C} \times 10 \mathrm{~min}\end{array}$ & $\begin{array}{c}500-\mu L \text { oyster } \\
\text { homogenate mixture } \\
\downarrow \\
+50-\mu L=10 \% \text { Triton } \\
\text { X-100 } \\
\downarrow \\
100^{\circ} \mathrm{C} \times 10 \mathrm{~min}\end{array}$ & $\begin{array}{c}500-\mu L \text { oyster } \\
\text { homogenate mixture } \\
\downarrow \\
+4-\mu \mathrm{L} \text { lysozyme } \\
(50 \mathrm{mg} / \mathrm{mL}) \\
\downarrow \\
37^{\circ} \mathrm{C} \times 15 \mathrm{~min} \\
\downarrow \\
+1-\mu \mathrm{L} \text { Proteinase } \mathrm{K} \\
(20 \mathrm{mg} / \mathrm{mL}) \\
\downarrow \\
60^{\circ} \mathrm{C} \times 30 \mathrm{~min} \\
\downarrow \\
100^{\circ} \mathrm{C} \times 10 \mathrm{~min}\end{array}$ \\
\hline
\end{tabular}

dilutions using PBS were prepared from the 1:10 diluted oyster homogenates. Three tubes of $10 \mathrm{~mL}$ of APW were inoculated with each serial dilution $\left(10^{-1}\right.$ to $\left.10^{-9}\right)$ of oyster samples. After incubation at $37^{\circ} \mathrm{C}$ for 16 to $18 \mathrm{~h}$, enrichment broths from all dilutions bearing at least 1 turbid tube, and at least 1 dilution higher were streaked on thiosulfate-citrate-bile salts sucrose (TCBS) agar (Difco). The plates were incubated at $37^{\circ} \mathrm{C}$ for 18 to $24 \mathrm{~h}$. Three or more typical V. parahaemolyticus colonies (green round colonies, 2- to 3-mm dia) were streaked onto TSAS for single colony isolation. Putative $V$. parahaemolyticus colonies were confirmed by screening for the presence of $t$ th using PCR. ORF8-PCR was also conducted on each isolate using the protocol described above.

\section{PCR on fresh oyster samples}

Three oyster lysate preparation methods, in combination with a 6 -h enrichment and the optimized $t h$ - and ORF8-PCR assays, were applied to test 4 batches of oyster samples, each containing 12 to 14 oysters. Enrichment controls for each batch were prepared by inoculating $30 \mathrm{~mL}$ of APW (without oysters) with $10^{8} \mathrm{~V}$. parahaemolyticus isolates FSL-Y1-002 ( $t$ lh-positive, ORF8negative), FSL-Y1-017 (th-positive, ORF8positive), and $V$. natriegens FSL-Y1-093 (th-negative, ORF8-negative). These controls were subjected to the same treatment as oyster samples. The negative control was APW (with neither oyster samples nor inoculated bacteria). For each batch, 5 1-mL aliquots of the 1:10 diluted oyster homogenates were each incubated with $30 \mathrm{~mL}$ of APW at $37^{\circ} \mathrm{C}$ for $6 \mathrm{~h}$. After enrichment, 500$\mu \mathrm{L}$ aliquots from each enrichment broth were used to prepare oyster lysates according to methods $\mathrm{A}, \mathrm{B}$, and $\mathrm{C}$ for $t \mathrm{lh}$ - and
ORF8-PCR. To determine the presence of PCR inhibitors, oyster lysates that were originally negative for ORF8-PCR were seeded with different dilutions $\left(10^{-2}\right.$ to $\left.10^{-8}\right)$ of a bacterial lysate prepared from FSL-Y1-018 (a V. parahaemolyticus O3:K6 isolate). Band intensities for oyster lysates seeded with bacterial lysates were compared with corresponding pure bacterial lysate dilutions to evaluate the presence of PCR inhibitors. A visibly weaker or absent band (of the correct size) in the seeded samples as compared to the pure bacterial lysate dilutions would be indicative for the presence of PCR inhibitors.

\section{Results and Discussion}

TN CONTRAST TO THE HISTORICAL SPORADIC 1 nature of most Vibrio parahaemolyticus infections, V. parahaemolyticus isolates bearing serotype O3:K6 have been linked to large-scale outbreaks, including 2 foodborne disease outbreaks in the United States in 1998. Sensitive and discriminatory detection methods for this pathogen are needed to assist in preventing the harvest and consumption of contaminated seafoods. To this end, our study was designed to develop and test a specific PCR-based detection method for V. parahaemolyticus O3:K6 that could be applied to screen seafood samples and bacterial colonies.

\section{Standard microbiological and other rapid methods for the detection of $V$. parahaemolyticus}

The current enumeration method for $V$. parahaemolyticus described in the BAM (FDA 2001) specifies a 3-tube MPN enrichment in APW or alkaline peptone salt broth followed by plating on TCBS agar. Colonies typical of $V$. parahaemolyticus are then subjected to a number of biochemical tests to 
distinguish $V$. parahaemolyticus from other marine vibrios. "Pathogenic" $V$. parahaemolyticus isolates are detected by screening isolates for the presence of $t d h$ by colony hybridization utilizing gene probes. Alternatively, the production of Tdh can be determined by the KP test. If isolates are $t d h$ - or KP-positive, they can be serotyped for further characterization. Practical limitations of this method thus include the number of steps involved, cost of supplies, and the time required for completion. Furthermore, this method only detects $V$. parahaemolyticus strains that bear $t d h$ or that produce Tdh. To allow specific identification of V. parahaemolyticus O3:K6, serotyping has to be performed in addition to the tests described above. The overall time required for specific detection of $V$. parahaemolyticus O3:K6 could thus be 4 to $6 \mathrm{~d}$.

The recognized limitations of the standard methods for detecting $V$. parahaemolyticus have prompted efforts to develop more rapid screening and detection assays for pathogenic V. parahaemolyticus. Many studies have focused specifically on the detection of $t d h$ - and trh-bearing V.parahaemolyticus, since these genes have been suggested as markers for virulence capacity. In addition to colony hybridization, other DNA-based methods, such as PCR, for the detection of $t d h$ and $t r h$ have been described (Lee and others 1992; Tada and others 1992; Lee and Pan 1993; Karunasagar and others 1996; Bej and others 1999). Further, a variety of antibody-based detection assays for V. parahaemolyticus have also been described. Honda and others (1995) used Tdh and Trh antibodies to detect hemolysin-expressing V. parahaemolyticus to overcome some of the potential drawbacks associated with the simple detection of $t d h$ and/or $t r h$ (that is, the simple presence of $t d h$ or $t r h$ does not ensure that the hemolysin is expressed and/or exported, hence PCR-positive strains actually may be non-pathogenic).

\section{Rationale for using PCR in this study}

Among a vast array of DNA-based detection methods (such as, colony hybridization, colorimetric dip stick hybridization), we selected PCR as the detection tool for $V$. parahaemolyticus O3:K6 due to its sensitivity and rapid nature. PCR is not only well recognized as an indispensable tool in many aspects of molecular biology, but it is also increasingly used in the food industry for detection of a variety of food-borne pathogens including Escherichia coli, Salmonella spp., Shigella spp., Yersinia enterocolitica, Clostridium perfringens (Vantarakis and oth- ers 2000; Augustynowicz and others 2002; Bayardelle and Zafarullah 2002; Knutsson and others 2002). The potential for using PCR-based assays for the detection of $V$. parahaemolyticus from seafoods has previously been demonstrated (Lee and others 1995; Karunasagar and others 1996; Bej and others 1999). For example, Bej and others (1999) described a multiplex PCR-based assay for the detection of V. parahaemolyticus in shellfish. In addition to detecting $t d h$ and $t r h$, this assay also targeted the gene encoding the thermolabile hemolysin $(t l h)$ to allow detection of all V. parahaemolyticus strains. Because PCR assays are becoming progressively more common in routine food testing laboratories, the simple yet sensitive and reliable PCR assay we developed is expected to represent a feasible and useful tool for many laboratories.

\section{Development and evaluation of a specific PCR assay for $V$. parahaemolyticus 03:K6}

To allow specific PCR detection of the $V$. parahaemolyticus O3:K6 clonal group (serotype O3:K6, O4:K68, and O1:KUT), it is critical to identify a genetic marker specific to this group. Since previous work by Nasu and others (2000) identified the eighth open reading frame (ORF8) of a filamentous phage f237 as a possible marker exclusively found in V. parahaemolyticus O3:K6, we chose a previously described ORF8-PCR primer set (Nasu and others 2000) for further verification and development of a sensitive $V$. parahaemolyticus O3:K6-specific PCR assay for application on food samples.

In our experiments, a total of $78 \mathrm{~V}$. parahaemolyticus isolates and other related species were initially tested with the speciesspecific thermolabile hemolysin gene ( $t l h)$ primer set (Bej and others 1999) to confirm their identities. All V. parahaemolyticus isolates were positive with this PCR assay (Table 1). In PCR with the ORF8 primer set, only the V. parahaemolyticus O3:K6 clonal group (37 V. parahaemolyticus O3:K6, 1 V. parahaemolyticus O1:KUT, and $1 \mathrm{~V}$. parahaemolyticus O4:K68) showed positive reactions (Table 1). Southern blot hybridizations with chromosomal DNA and ORF8 probes were conducted on 4 nonO3:K6 (FSL-Y1-002, FSL-Y1-008, FSL-Y1-010, and FSL-Y1-012) and 4 O3:K6 (FSL-Y1-014, FSL-Y1-015, FSL-Y1-016, and FSL-Y1-037) isolates to confirm PCR results. The nonO3:K6 isolates were negative for the presence of ORF8, whereas the O3:K6 isolates possessed a visible band in the Southern blot hybridization (data not shown). Our results thus confirm, using a large strain collection, which ORF8 provides a specific tar- get for the PCR detection of the V. parahaemolyticus O3:K6 clonal group. In a comparative study of toxRS and ORF8 PCR assays, Osawa and others (2002b) also reported that the presence of ORF8 was a reliable marker for detection of pandemic $V$. parahaemolyticus O3:K6 strains among $24 \mathrm{~V}$. parahaemolyticus strains that had been isolated in Japan, the US, Thailand, Indonesia, and Korea. This collection included $21 \mathrm{~V}$. parahaemolyticus O3:K6 strains (12 isolated before 1996; 9 after 1996) and 3 O4:K68 strains. On the other hand, Bhuiyan and others (2002) screened a collection of 66 clinical V. parahaemolyticus strains classified to 14 serotypes that had been isolated in Bangladesh from 1988 to 2000. Eight of $28 \mathrm{~V}$. parahaemolyticus O3:K6 strains were reported to be PCR-negative for ORF8. The authors hypothesized that loss of ORF8 might result from loss of some or all of phage 237 . In combination, the accumulated evidence suggests that the ORF8 assay reported herein might be most appropriately applied in a multiplex PCR format that also targets other relevant genes specifically associated with the O3:K6 clonal group.

In addition to specificity, sensitivity represents an important consideration in the development of any diagnostic assay. We thus determined, in preliminary experiments, the sensitivity of both the $t h$ - and the ORF8-PCR assays using different dilutions of bacterial lysates prepared from enumerated overnight cultures of 6 isolates (FSL-Y1-002, FSL-Y1-017, FSL-Y1-018, FSLY1-054, FSL-Y1-063, and FSL-Y1-074). The sensitivity of the $t h$ - and ORF8-PCR were found to be $13.1 \pm 11.1$ (mean of all 6 isolates $\pm \mathrm{SD}$ ) and $2.3 \pm 0.4$ cells per PCR reaction, respectively. These results were verified by a second independent experiment with strain FSL-Y1-017, which showed a sensitivity of 2.1 cells per reaction for both $t h$ - and ORF8-PCR. Values for the first experiment were 1.7 cells per reaction for both $t h$ - and ORF8-PCR. An illustration of results from sensitivity determination experiments for the ORF8-PCR is shown in Figure 1. These results indicate that PCR primers and conditions used in these experiments provide a sensitive assay, well within the range of other sensitive PCR-based detection methods.

\section{Optimization of PCR assay using inoculated oyster samples}

Although PCR-based detection and characterization of pure bacterial cultures (as applied in the previous section) are generally straightforward, application of a PCRbased assay to screen food samples for the presence of specific bacterial pathogens is considerably more challenging, particular- 
ly due to the difficulty of effective isolation of sufficiently pure bacterial (or total) DNA from food samples. We thus tested 4 oyster lysate preparation methods, which were adopted from previous studies (Lee and others 1995; Brasher and others 1998), for their relative abilities to provide suitable DNA for PCR amplification detection from inoculated samples of canned oysters, without enrichment or following a short enrichment in APW. Since preliminary experiments showed that method D (Chelex ${ }^{\mathrm{TM}}$ 100) was both the most time-consuming approach, and also provided inconsistent results (data not shown), only methods $\mathrm{A}, \mathrm{B}$, and $\mathrm{C}$ were used in our main experiments.

To initially determine the sensitivities of the $t h$ - and ORF8-PCR assays on oyster samples, different bacterial cell concentrations of 2 isolates (FSL-Y1-054 and FSL-Y1-063) were inoculated into 1:10 diluted canned oyster homogenates prior to 6 -h enrichment, oyster lysate preparation and PCR. Detection sensitivities achieved with all 3 DNA preparation methods (A, B, and C; Table 2) were the same. On average, both the tlh- and ORF8-PCR could detect 310 bacterial cells per $\mathrm{g}$ of oyster. To further probe the effect of enrichment time and DNA preparation method, samples of canned oysters were inoculated with each of 33 different $V$. parahaemolyticus isolates of known serotypes (Table 1) in a concentration of $10^{7}$ to $10^{8}$ cells per $\mathrm{mL}$ of $1: 10$ diluted oyster homogenates (equivalent to $10^{8}$ to $10^{9}$ bacterial

Table 3-Results of $t / h$ - and ORF8-PCR using 3 DNA preparation methods on inoculated canned oyster samples after 0,6 , and $18 \mathrm{~h}$ of enrichment

\begin{tabular}{|c|c|c|c|c|}
\hline & \multicolumn{2}{|c|}{ tlh-PCR results ${ }^{a}$} & \multicolumn{2}{|c|}{ ORF8-PCR results ${ }^{a}$} \\
\hline & $\begin{array}{l}\text { V. parahae- } \\
\text { molyticus } \\
\text { non-03:K6 } \\
\text { isolates } \\
(\mathrm{n}=15)\end{array}$ & $\begin{array}{l}\text { V. parahae- } \\
\text { molyticus } \\
\text { O3:K6 } \\
\text { isolates } \\
(\mathrm{n}=18)\end{array}$ & $\begin{array}{l}\text { V. parahae- } \\
\text { molyticus } \\
\text { non-03:K6 } \\
\text { isolates } \\
(\mathrm{n}=15)\end{array}$ & $\begin{array}{l}\text { V. parahae- } \\
\text { molyticus } \\
\text { O3:K6 } \\
\text { isolates } \\
(\mathrm{n}=18)\end{array}$ \\
\hline \multicolumn{5}{|c|}{ O-h enrichment } \\
\hline Method A & $13(86.7 \%)$ & $18(100 \%)$ & $0(0 \%)$ & $17(94.4 \%)$ \\
\hline Method B & $10(66.7 \%)$ & $12(66.7 \%)$ & $0(0 \%)$ & $2(11.1 \%)$ \\
\hline Method C & $3(20 \%)$ & $0(0 \%)$ & $0(0 \%)$ & $0(0 \%)$ \\
\hline All methods & $13(86.7 \%)$ & $18(100 \%)$ & $0(0 \%)$ & $17(94.4 \%)$ \\
\hline \multicolumn{5}{|c|}{ 6-h enrichment } \\
\hline Method A & $14(93.3 \%)$ & $18(100 \%)$ & $0(0 \%)$ & $18(100 \%)$ \\
\hline Method B & $15(100 \%)$ & $18(100 \%)$ & $0(0 \%)$ & $18(100 \%)$ \\
\hline Method C & $15(100 \%)$ & $18(100 \%)$ & $0(0 \%)$ & $18(100 \%)$ \\
\hline All methods & $15(100 \%)$ & $18(100 \%)$ & $0(0 \%)$ & $18(100 \%)$ \\
\hline \multicolumn{5}{|c|}{ 18-h enrichment } \\
\hline Method A & $14(93.3 \%)$ & $18(100 \%)$ & $0(0 \%)$ & $17(94.4 \%)$ \\
\hline Method B & $14(93.3 \%)$ & $18(100 \%)$ & $0(0 \%)$ & $17(94.4 \%)$ \\
\hline Method C & $14(93.3 \%)$ & $18(100 \%)$ & $0(0 \%)$ & $17(94.4 \%)$ \\
\hline All methods & $15(100 \%)$ & $18(100 \%)$ & $0(0 \%)$ & $17(94.4 \%)$ \\
\hline
\end{tabular}

aData represent the number (and the percentage) of isolates with positive results.

cells per gram of oyster). After enrichment of the inoculated oyster samples for $0 \mathrm{~h}$ (without enrichment broth), $6 \mathrm{~h}$ and $18 \mathrm{~h}$, oyster lysate preparation methods $\mathrm{A}, \mathrm{B}$, and C were used to isolate total DNA for subsequent $t$ lh- and ORF8-PCR. The PCR results are summarized in Table 3. Even with large numbers of inoculated bacteria used in these studies, direct DNA isolation without enrichment ("0 h enrichment”) yielded

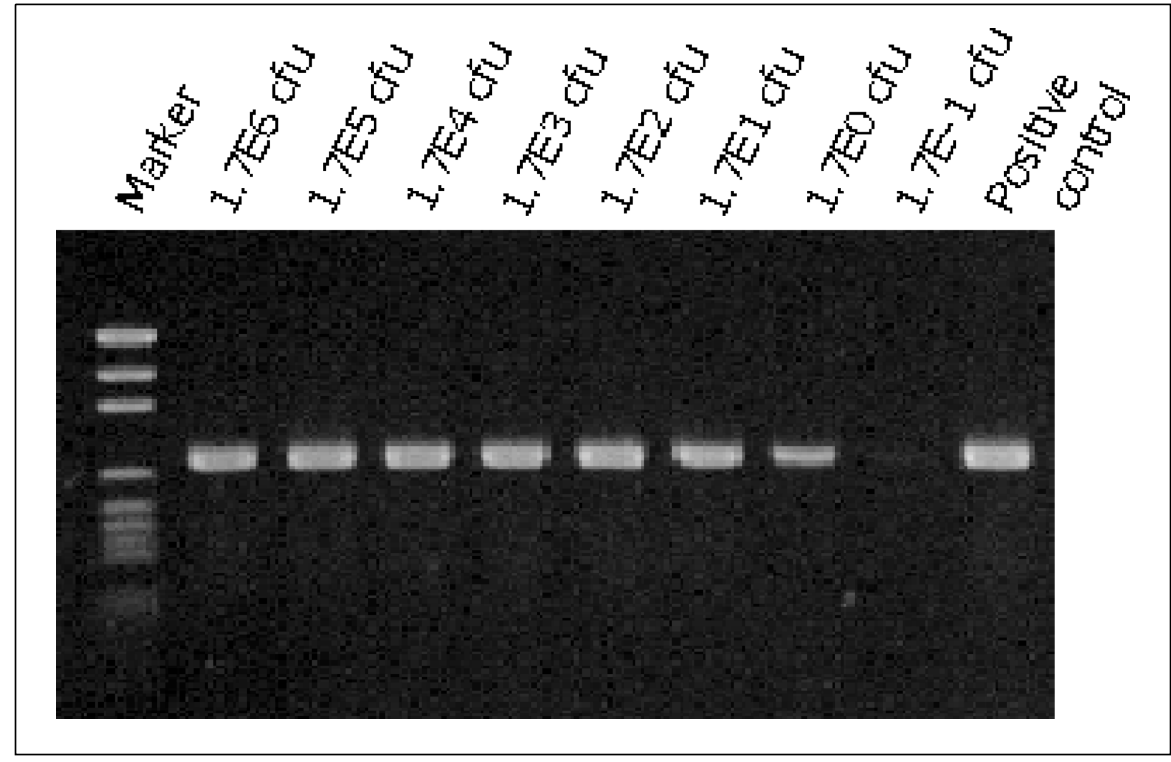

Figure 1-Representative gel image of sensitivity determination. Different dilutions of enumerated bacterial lysates (FSL-Y1-017) were used in this ORF8PCR. The sensitivity, or detection limit, for this PCR was 1.7 cells per reaction. PCR conducted without bacterial lysate addition (negative control) showed no band (data not shown). some false-negative results. Without an enrichment step, methods A and B appeared to be more effective at providing DNA than method C. A 6-h enrichment followed by PCR yielded $100 \%$ ORF8-PCR sensitivity with all inoculated samples, regardless of DNA preparation method. On the other hand, a prolonged enrichment (18 h) appeared to have a negative effect on assay sensitivity, possibly due to PCR inhibition from an excessive amount of DNA generated by overgrown $V$. parahaemolyticus. We thus conclude that a 6 -h pre-PCR enrichment step reduces the frequency of falsenegative results. Although this enrichment step increases the overall time required for assay completion, a short selective enrichment provides a number of benefits. First, enrichment increases the number of V. parahaemolyticus target cells present, thereby improving assay sensitivity. An enrichment step can also resuscitate $V$. parahaemolyticus to allow recovery of injured cells. Further, a selective enrichment provides the advantage of suppressing other bacteria. The dilution effect inherent in an enrichment procedure also reduces the risks of PCR inhibition by reducing concentrations of sample components.

Testing of fresh and uninoculated oyster samples using PCR

After validation of the $t$ lh- and ORF8-PCR assays on inoculated oyster samples, we further evaluated these assays for their abilities to detect V.parahaemolyticus in oyster samples. For each of the 4 batches of oysters, a single 6-h enrichment in APW was 
performed. A total of $15500-\mu \mathrm{L}$ aliquots from each batch were collected and 5 aliquots each were used to prepare oyster lysates with methods $A, B$, and $C$, respectively. A batch showing a positive $t$ lh- or ORF8-PCR result on any of these oyster lysate aliquots would be considered positive for $V$. parahaemolyticus or V. parahaemolyticus O3:K6, respectively. As summarized in Table 4, all 4 batches were positive for V. parahaemolyticus, whereas none were positive by the $V$. parahaemolyticus O3:K6-specific ORF8PCR. A representative gel image is shown in Figure 2. Oyster lysate preparation method A yielded a total of 19 positive $t$ lh PCR results, followed by methods B and C (17 and 14 positive $t$ lh PCR results, respectively). A recognized drawback of PCR applied on food samples is the existence of PCR inhibitors in food products, which can lead to false-negative results (Lantz and others 2000). To exclude the possibility of false negative results due to PCR inhibition, we tested 1 oyster lysate from each batch and from each oyster lysate preparation method after seeding each sample with various dilutions of a bacterial lysate from $V$. parahaemolyticus O3:K6 FSL-Y1-018 prior to ORF8-PCR. The band intensities from seeded oyster lystates were similar to those from the corresponding bacterial lysates (Figure 3), suggesting PCR inhibitors were not present or were removed by the extraction methods.

In parallel to screening with the PCR assays described above, all batches of oyster samples were also tested using the standard microbiological (BAM) method with some modifications. Batches 1 and 2 were tested qualitatively by enrichment in APW followed by plating on TCBS for single colony isolation. Both batches tested positive for V. parahaemolyticus. Batches 3 and 4 were tested quantitatively using a 3-tube MPN estimation with plating on TCBS for single colony isolation. The MPN of $V$. parahaemolyticus in batch 3 and batch 4 were 230 $\mathrm{MPN} / \mathrm{g}$ (confidence interval $=66$ to 800 $\mathrm{MPN} / \mathrm{g}$ ) and $430 \mathrm{MPN} / \mathrm{g}$ (confidence interval $=100$ to $1700 \mathrm{MPN} / \mathrm{g}$ ), respectively. These MPN values further confirm the sensitivity of our $t$ lh-PCR, which was estimated to have a sensitivity of $310 \mathrm{~V}$. parahaemolyticus cells/g based on artificially inoculated oyster samples. Overall, we obtained a total of 108 (batch 1: 28; batch 2: 24; batch 3: 22; batch 4: 34) putative V. parahaemolyticus isolates from all batches. PCR detection of $t$ th was used on each isolate to confirm its species identification. There were 26, 20, 22, and 18 isolates positive for $t h$ in batch 1,2 , 3 , and 4 , respectively. On the other hand, none of these isolates were positive in ORF8-PCR (Table 4). These results suggest
Table 4-Summary of t/h- and ORF8-PCR on fresh and uninoculated oyster samples using 3 oyster lysate preparation methods

\begin{tabular}{|c|c|c|c|c|c|}
\hline \multicolumn{3}{|c|}{$\begin{array}{c}\text { tlh-PCR }^{\mathrm{a}} \\
\text { (V. parahaemolyticus) }\end{array}$} & \multicolumn{3}{|c|}{$\begin{array}{c}\text { ORF8-PCR }^{\mathrm{a}} \\
\text { (V. parahaemolyticus 03:K6) }\end{array}$} \\
\hline $\begin{array}{l}\text { Method A } \\
(n=5)\end{array}$ & $\begin{array}{l}\text { Method B } \\
(n=5)\end{array}$ & $\begin{array}{l}\text { Method C } \\
(n=5)\end{array}$ & $\begin{array}{l}\text { Method A } \\
(n=5)\end{array}$ & $\begin{array}{l}\text { Method B } \\
(n=5)\end{array}$ & $\begin{array}{l}\text { Method C } \\
(n=5)\end{array}$ \\
\hline \multicolumn{6}{|l|}{ Dyster batch } \\
\hline 4 & 4 & 3 & 0 & 0 & 0 \\
\hline 4 & 3 & 2 & 0 & 0 & 0 \\
\hline 5 & 5 & 5 & 0 & 0 & 0 \\
\hline 4 & 5 & 4 & 0 & 0 & 0 \\
\hline
\end{tabular}

aData represents the number of aliquots yielding positive result. A batch showing a positive $t / h$ - or ORF8-PCR result on any of these oyster lysate aliquots would be considered positive for $V$. parahaemolyticus or $V$. parahaemolyticus O3:K6, respectively.

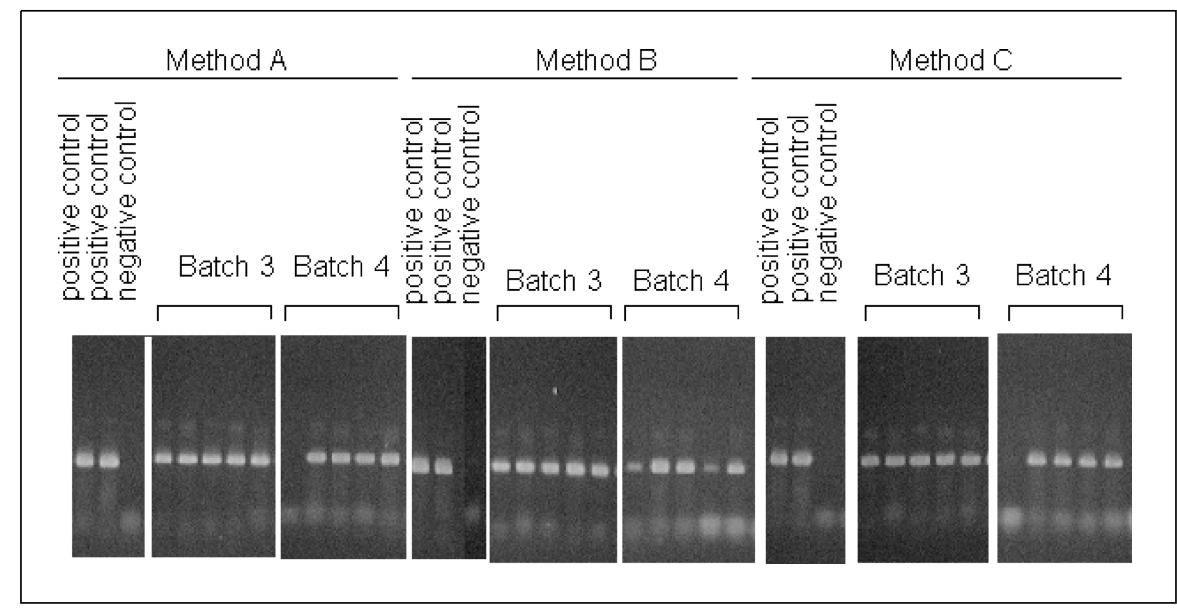

Figure 2-Results of $t / h-P C R$ for batch \#3 and \#4 of fresh oyster samples. Positive enrichment controls are V. parahaemolyticus FSL-Y1-002 and FSL-Y1017. Negative enrichment control is $V$. natriegens FSL-Y1-093.

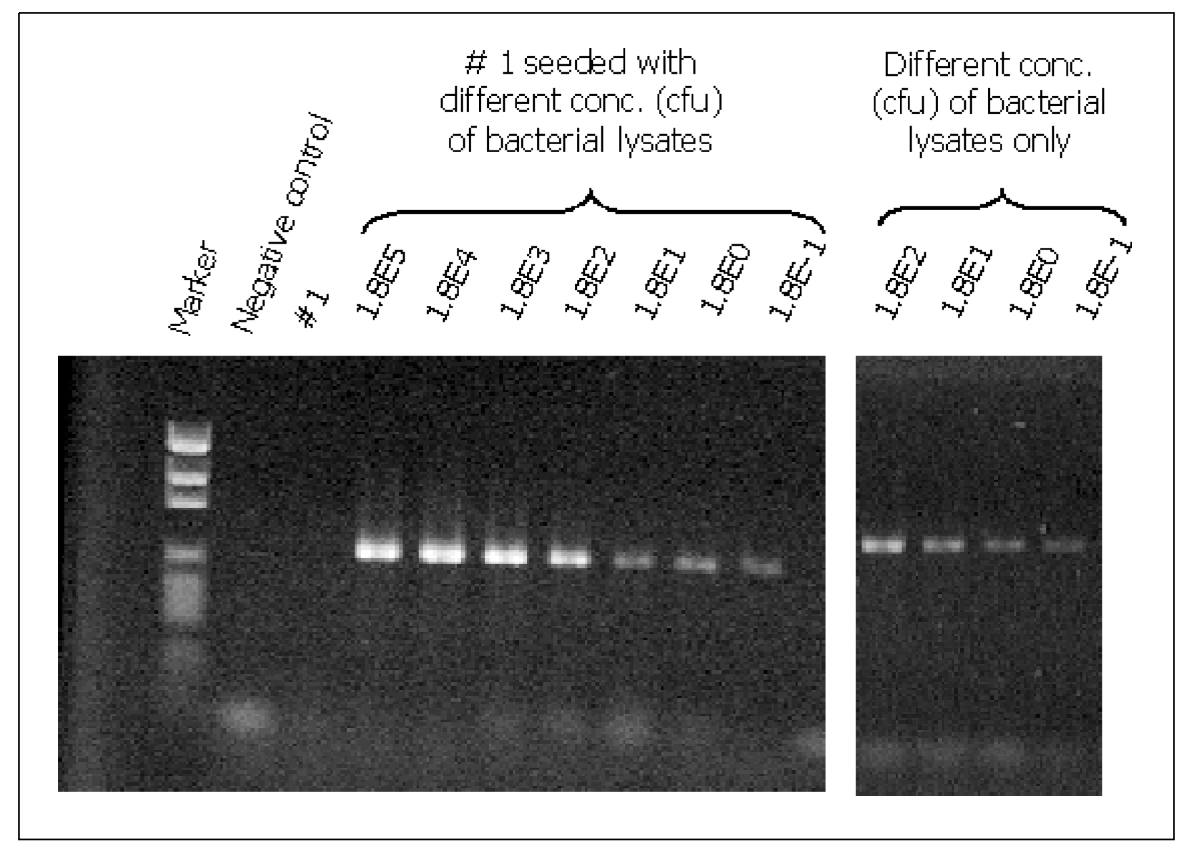

Figure 3-Screening of PCR inhibition. ORF8-negative oyster lysate from batch \# 1 was seeded with different dilutions of a bacterial lysate (V. parahaemolyticus 03:K6 FSL-Y1-018). The band intensities of the seeded oyster lysates were similar to those from the corresponding bacterial lysate dilutions, suggesting PCR inhibitors were not present or were removed by the extraction methods. 
all batches of oysters contained V. parahaemolyticus, but none harbored the pandemic clone of serotype O3:K6. These results confirmed those obtained by PCR and indicate that the PCR assay described here provides specific detection of $V$. parahaemolyticus comparable to that of current standard methods.

\section{Conclusions}

$\mathrm{W}^{\mathrm{a}}$ E DESCRIBE THE APPLICATION OF A PCR assay for sensitive and specific detection of $V$. parahaemolyticus O3:K6, a pandemic strain that has caused a number of large-scale human food-borne disease outbreaks in recent years. We showed that this assay can be applied as a rapid screening tool for V. parahaemolyticus O3:K6 in oyster samples, when combined with a 6-h enrichment. Compared with the current standard method for oyster samples, our assay greatly improves the speed of the detection of $V$. parahaemolyticus O3:K6 by providing results within $1 \mathrm{~d}$. This PCR-based method thus could be incorporated into standard procedures as a screening and monitoring tool for harvest waters and oyster samples for $V$. parahaemolyticus O3:K6. We also showed that this assay could be combined with a previously described (Bej and other 1999) $t h$-PCR assay to screen for the presence of all V. parahaemolyticus serotypes.

\section{References}

Augustynowicz E, Gzy A, Slusarczyk J. 2002. Detection of enterotoxigenic Clostridium perfringens with a duplex PCR. J Med Microbiol 51(2):169-72.

Ausubel FM, Brent R, Kingston RE, Moore DD, Seidman JG, Smith JA, Struhl K, editors. 1995. Current protocols in molecular biology. New York: John Wiley \& Sons. Sec. 2.9A.

Baross J, Liston J. 1968. Isolation of Vibrio parahaemolyticus from the Northwest Pacific. Nature 217(135):1263-4

Bayardelle P, Zafarullah M. 2002. Development of oligonucleotide primers for the specific PCR-based detection of the most frequent Enterobacteriaceae species DNA using wec gene templates. Can $\mathrm{J} \mathrm{Mi}$ crobiol 48(2):113-22.

Bej AK, Patterson DP, Brasher CW, Vickery MC, Jones DD, Kaysner CA. 1999. Detection of total and hemolysin-producing Vibrio parahaemolyticus in shellfish using multiplex PCR amplification of $t l$, $t d h$ and $t r h$. J Microbiol Methods 36:215-25.

Bhuiyan NA, Ansaruzzaman M, Kamruzzaman M, Alam K, Chowdhury NR, Nishibuchi M, Faruque SM, Sack DA, Takeda Y, Nair GB. 2002. Prevalence of the pandemic genotype of Vibrio parahaemolyticus in Dhaka, Bangladesh, and significance of its distribution across different serotypes. J Clin Microbio $40(1): 284-6$.

Brasher CW, DePaola A, Jones DD, Bej AK. 1998. Detection of microbial pathogens in shellfish with multiplex PCR. Curr Microbiol 37(2):101-7.

[CDC] Centers for Disease Control and Prevention. 1998. Outbreak of Vibrio parahaemolyticus infections associated with eating raw oysters -Pacific Northwest, 1997. Morbid Mortal Wkly Rep
47(22):457-62.

[CDC] Centers for Disease Control and Prevention. 1999. Incidence of food-borne illnesses: preliminary data from the food-borne diseases active surveillance network (FoodNet) - United States, 1998. Morbid Mortal Wkly Rep 48(9):189-94

[CDC] Centers for Disease Control and Prevention. 2002. Preliminary FoodNet data on the incidence of food-borne illnesses-selected sites, United States, 2001. Morbid Mortal Wkly Rep 51(5):325-9.

Chowdhury NR, Chakraborty S, Ramamurthy T, Nishibuchi M, Yamasaki S, Takeda Y, Nair GB. 2000. Molecular evidence of clonal Vibrio parahaemolyticus pandemic strains. Emerg Infect Dis 6:631-6.

Daniels NA, Ray B, Easton A, Marano N, Kahn E, McShan II AL, Del Rosario L, Baldwin T, Kingsley MA, Puhr ND, Wells JG, Angulo FJ. 2000. Emergence of a new Vibrio parahaemolyticus serotype in raw oysters: A prevention quandary. JAMA 284(12):1541-5.

[FDA] Food and Drug Administration. 2001. Bacteriological analytical manual online. Washington, D.C.: Food and Drug Administration. Available from: <http://www.cfsan.fda.gov/ ebam/bam-9.html>. Posted Jan. 2001

Hlady WG, Klontz KC. 1996. The epidemiology of Vibrio infections in Florida, 1981-1993. J Infect Dis 173(5):1176-83.

Honda T, Miwatani T, Yabushita Y, Koike N, Okada K. 1995. A novel method to chemically immobilize antibody on nylon and its application to the rapid and differential detection of 2 Vibrio parahaemolyticus toxins in a modified enzyme-linked immunosorbent assay. Clin Diagn Lab Immunol 2:177-81

Karunasagar I, Sugumar G, Reilly PJ. 1996. Rapid polymerase chain reaction method for detection of Kanagawa positive Vibrio parahaemolyticus in seafoods. Int J Food Microbiol 31:317-23.

Kelly MT, Stroh EMD. 1989. Urease-positive Kanagawa-negative Vibrio parahaemolyticus from patients and the environment in the Pacific Northwest. J Clin Microbiol 27:2820-2

Khan AA, McCarthy S, Wang RF, Cerniglia CE. 2002. Characterization of United States outbreak isolates of Vibrio parahaemolyticus using enterobacterial repetitive intergenic consensus (ERIC) PCR and development of a rapid PCR method for detection of O3:K6 isolates. FEMS Microbiol Lett 206(2):20914.

Knutsson R, Blixt Y, Grage H, Borch E, Radstrom P. 2002. Evaluation of selective enrichment PCR procedures for Yersinia enterocolitica. Int J Food Microbiol 73(1):35-46.

Lantz, PG, Abu al-SW, Knutsson R, Hahn-Hagerdal B, Radstrom P. 2000. Biotechnical use of polymerase chain reaction for microbiological analysis of bio logical samples. Biotechnol Annu Rev 5:87-130.

Lee C, Pan SF. 1993. Rapid and specific detection of the thermostable direct haemolysin gene in Vibrio parahaemolyticus by the polymerase chain reaction. J Gen Microbiol 139:3225-31.

Lee C, Chen LH, Liu ML, Su YC. 1992. Use of an oligonucleotide probe to detect Vibrio parahaemolyticus in artificially contaminated oysters. Appl Environ Microbiol 58:3419-22.

Lee CY, Pan SF, Chen CH. 1995. Sequence of a cloned pR72H fragment and its use for detection of Vibrio parahaemolyticus in shellfish with the PCR. Appl Environ Microbiol 61(4):1311-7.

Matsumoto C, Okuda J, Ishibashi M, Iwanaga M, Garg P, Rammamurthy T, Wong HC, Depaola A, Kim YB, Albert MJ, Nishibuchi M. 2000. Pandemic spread of an O3:K6 clone of Vibrio parahaemolyticus and emergence of related strains evidenced by arbitrarily primed PCR and toxRS sequence analyses. J Clin Microbiol 38:578-85.

Miyamoto Y, Kato T, Obara Y, Akiyama S, Takizawa K, Yamai S. 1969. In vitro hemolytic characteristics of Vibrio parahaemolyticus: its close correlation with human pathogenicity. J Bact 100:1147-9.

Murase M, Kurokawa M, Nukina M, Nakanishi H, Haruta T. 2001. Surveillance of various entero- pathogenic bacteria from diarrheal cases during 1989-1999 in Kobe City. Kansenshogaku Zasshi 75(10):883-93.

Nasu H, Iida T, Sugahara T, Yamaichi Y, Park KS Yokoyama K, Makino K, Shinagawa H, Honda T. 2000. A filamentous phage associated with recent pandemic Vibrio parahaemolyticus O3:K6 strains. J Clin Microbiol 38:2156-61.

Nishibuchi M, Ishibashi M, Takeda Y, Kaper JB. 1985 Detection of the thermostable direct hemolysin gene and related DNA sequence in Vibrio parahaemolyticus and other Vibrio species by DNA colony hybridization test. Infect Immun 49:491-6.

Okuda J, Ishibashi M, Hayakawa E, Nishino T, Takeda Y, Mukhopadhyay AK, Garg S, Bhattacharya SK, Nair GB, Nishibuchi M. 1997. Emergence of a unique O3:K6 clone of Vibrio parahaemolyticus in Calcutta, India, and isolation of strains from the same clonal group from Southeast Asian travelers arriving in Japan. J Clin Microbiol 35(12):3150-5.

Osawa R, Arakawa E, Okitsu T, Yamai S, Watanabe H. 2002a. Levels of thermostable direct hemolysin produced by Vibrio parahaemolyticus O3:K6 and other serovars grown anaerobically with the presence of a bile acid. Curr Microbiol 44(4):302-5.

Osawa R, Iguchi A, Arakawa E, Watanabe H. 2002b. Genotyping of pandemic Vibrio parahaemolyticus O3:K6 still open to question. J Clin Microbiol 40(7):2708-9

Pan TM, Wang TK, Lee CL, Chien SW, Horng CB. 1997. Food-borne disease outbreaks due to bacteria in Taiwan, 1986-1995. J Clin Microbiol 35(5):1260-2. Shirai H, Ito H, Hirayama T, Nakamoto Y, Nakabayashi N, Kumagai K, Takeda Y, Nishibuchi M. 1990. Molecular epidemiologic evidence for association of thermostable direct hemolysin (TDH) and TDHrelated hemolysin of Vibrio parahaemolyticus with gastroenteritis. Infect Immun 58:3568-73.

Tada J, Ohashi T, Nishimura N, Shirasaki Y, Ozaki H, Fukushima S, Takano J, Nishibuchi M, Takeda Y. 1992. Detection of the thermostable direct hemolysin gene $(t d h)$ and the thermostable direct hemolysinrelated hemolysin gene (trh) of Vibrio parahaemolyticus by polymerase chain reaction. Mol Cell Probes 6:477-87.

Vantarakis A, Komninou G, Venieri D, Papapetropoulou M. 2000. Development of a multiplex PCR detection of Salmonella spp. and Shigella spp. in mussels. Lett Appl Microbiol 31:105-9.

Wong HC, Liu SH, Wang TK, Lee CL, Chiou CS, Liu DP, Nishibuchi M, Lee BK. 2000. Characteristics of Vibrio parahaemolyticus O3:K6 from Asia. Appl Environ Microbiol 66(9):3981-6.

Yeung PSM, Hayes MC, DePaola A, Kaysner CA, Kornsterin L, Boor KJ. 2002. Comparative phenotypic, molecular and virulence characterization of Vibrio parahemolyticus O3:K6 isolates. Appl Environ Microbiol 68(6):2901-9.

MS 20020641 Submitted 11/9/02, Revised 1/3/03, Accepted 1/28/03, Received 1/31/03

We are grateful to Martin Wiedmann of Cornell Univ. for providing intellectual discussion and technical advice. We are also grateful to Leonora Porter of the New York State Dept. of Environmental Conservation for collecting fresh oysters. We would like to thank Suzanne Barth of the Texas Dept. of Health for Texas isolates; Tim Root of the New York State Dept. of Health for NY isolates; Bob Howard of the Connecticut Dept. of Public Health for Connecticut isolates; and Mitsuaki Nishibuchi of Kyoto Univ. for Asian isolates. This work was supported by the Cooperative State Research, Education, and Extension Service, National Research Initiative Competitive Grants Program (NRI Proposal $\mathrm{nr}$ 199902756) of the United States Dept. of Agriculture.

Authors Marie Yeung and Boor are with the Dept. of Food Science, Cornell Univ., Ithaca, NY 14853 Author DePaola is with the Gulf Coast Seafood Laboratory, Food and Drug Administration, Dauphin Island, AL 36528. Author Kaysner is with Seafood Products Research Center, Food and Drug Administration, Bothell, WA 98021. Direct inquiries to author Boor (E-mail: kjb4@cornell.edu). 